\title{
Reducing the Burden of High Level Radioactive Waste with Transmutation — Proposal of Integral Molten Salt Fast Reactor (IMSFR)
}

\author{
Michio Yamawaki ${ }^{a, *}$ and Tadafumi Koyama ${ }^{b}$ \\ ${ }^{a}$ Research Institute of Nuclear Engineering, University of Fukui, 1-2-4 Kanawa-cho, Tsuruga, Fukui 914-0055, \\ Japan \\ ${ }^{b}$ Central Research Institute of Electrical Power Industries, 2-11-1 Iwadokita, Komae, Tokyo 201-8511, Japan
}

\section{Received September 7, 2016; Accepted October 12, 2016}

The transmutation methods to reduce the burden of high level radioactive waste had been compared to identify the most suitable method for this purpose. The results showed that the molten salt reactor (MSR) was suggested to be an effective transmutation system. Based on this result, a new concept of Integral Molten Salt Fast Reactor (IMSFR) as a highly efficient transmutation system for transuranium elements has been proposed in this study; the system consists of a combination of an MSR fuelled with chloride molten salt fuel and the chloride-based pyrochemical processing subsystem. In this system MSR fuel can be transferred between the reactor core and the pyrochemical processing subsystem without chemical form change.

\section{Introduction}

After the Fukushima nuclear accident, the public acceptance of nuclear energy use has become more severe than ever. The public's concern stems not only from the worry over the safety of nuclear power plants (NPPs) but also from that over the management of high level radioactive waste (HLW). In order to alleviate the public's concern over the management of HLW, transmutation of long-lived radioactive nuclides can be an effective measure from the viewpoint of reducing the life, heat and toxicity of HLW. The three systems of fast reactor (FR), accelerator-driven system (ADS) and molten salt reactor (MSR) are compared in terms of the efficiency of transmutation of HLW or minor actinide (MA) waste, the main component of HLW.

\section{Effect of transmutation for managing HLW}

Transmutation means to turn nuclei of long-lived trans-uranium (TRU) elements to short-lived nuclei by nuclear fission. Figure 1 shows the decrease of potential radiotoxicity of each group of radioactive materials constituting the HLW with elapse of time [1]. The radiotoxicity of HLW would decrease down to the level of natural uranium after $400 \mathrm{y}$ of storage in case of recycling of $99.5 \%$ of uranium and TRU, where recycling means separation and burning for transmutation. Thus, transmutation is effective to drastically shorten the timelength necessary to keep HLW in controlled safe condition.

As for transmutation techniques, FR, ADS and MSR have been proposed as the main candidates $[2,3]$.

2.1. FR. For FR cases, the low concentration of MA in mixed oxide fuel (MOX) causes a low transmutation rate in FR. Generally less than $5 \%$ concentration of MA is assumed in FR fuel mainly from the consideration of sodium void reactivity problem [4-6]. The sodium void reactivity is increased with the amount of MA in MOX fuel, a serious problem from the safety point of view. As measures to alleviate this prob-

*1Corresponding author. E-mail: myamaw@mug.biglobe.ne.jp, TEL: +81-047-345-7038 Fax: +81-047-345-7038

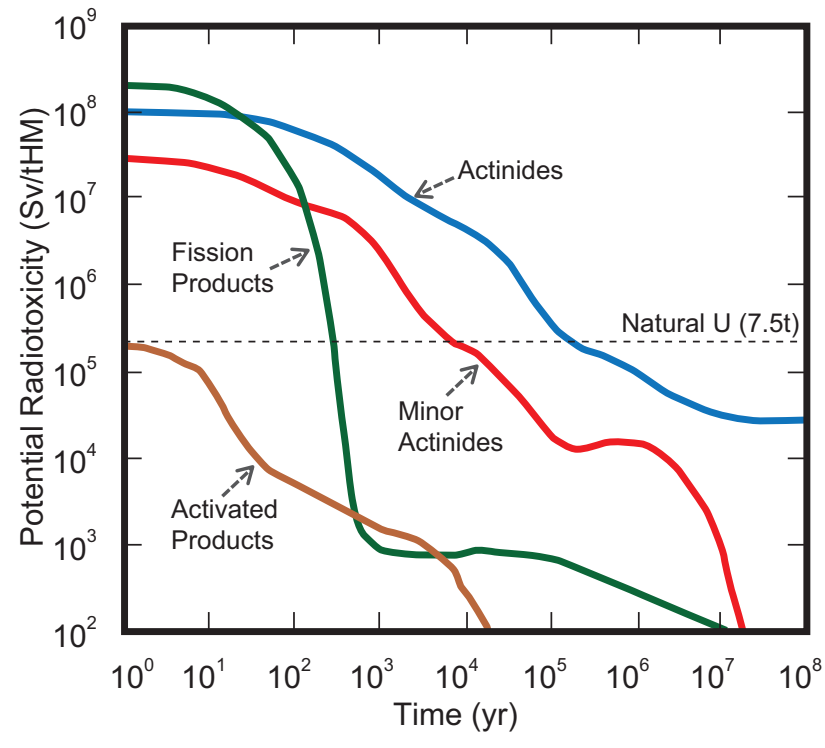

Figure 1. Potential radiotoxicity of radioactive nuclides generated in the fuel cycle of LWRs (normalized to 1 ton of new fuel) [1].

lem, Na plenum and/or ZrHx-added internal blanket are under investigation in ASTRID project of France [7] in collaboration with Japan Atomic Energy Agency (JAEA) and others [4]. The MA transmutation rate in FR has been estimated to attain about $70 \%$ reduction of MA in case of irradiation of 3-4 wt $\%$ MA-containing mixed oxide fuel there for nearly 150 years [4].

As a measure to increase MA transmutation rate, Yamawaki and his co-authors proposed a concept of MA hydride fuelloaded FR [8], where hydrogen atoms moderate neutron energy so as to increase the nuclear reaction rate contributing to increase of MA transmutation rate. Thus-obtained transmutation rate was estimated to be higher than that predicted for ADS as described in the next section [9].

2.2. ADS. The merit of ADS in regard of MA transmutation is that high neutron fluxes can be available thanks to spallation of neutron irradiation target to be brought about through bombardment with a high energy proton beam. 
According to Oigawa et al. [10-12], JAEA, transmutation of $250 \mathrm{~kg}$ MA can be achieved with 300 day operation of one $800 \mathrm{MWt}$ ADS, corresponding to the amount of MA generated in ten light water reactors operated for 1 year each.

However, to realize such an advanced system, new technologies such as a high performance proton accelerator and highly irradiation-resistant material should be developed. Thus, a lot of works need to be made before commercialization of ADS in the future.

2.3. MSR. For MSR cases, higher MA solubilities can be expected in molten salts. TRU solubility in FLiNaK ( $\mathrm{LiF}+\mathrm{NaF}+\mathrm{KF}$ mixture) is reported to be nearly $10 \%$, while that in chloride molten salt $(\mathrm{NaCl}$ or $\mathrm{NaCl}+\mathrm{KCl})$ is much higher, with even $50 \%$ or higher values to be possible [13]. In addition, fission products can be separated from the molten salt fuel on operation. Thus, MA transmutation rate can be expected to be much higher compared to FR and even to ADS.

According to Mitachi [14], about $96 \%$ of TRU can be reduced with two cycles of reactor irradiation for about 90 years in total using (FLiNaK+TRU)-fuelled MSR with uranium excluded. This performance is much better compared with that by FR as described above, i.e. about $70 \%$ reduction of MA in case of irradiation of 3-4 wt $\%$ MA containing mixed oxide fuel in FR for nearly 150 years.

Yamawaki et al. [15] proposed a concept of static-fuel-type MSR (S-MSR) which is composed of a cylindrical core tank filled with molten salt fuel and a vessel surrounding the core tank, filled with molten salt such as FLiNaK. This type MSR is extremely safe from the viewpoint of severe accidents since the molten salt fuel is confined in the core tank without circulation to the outside of the core.

\section{Integral Molten Salt Fast Reactor (IMSFR)}

Recently, Yamawaki proposed a new system, Integral Molten Salt Fast Reactor (IMSFR), in December, 2015 [16]. The system combined an MSR fueled with chloride molten salt fuel and a chloride-based pyrochemical processing subsystem.

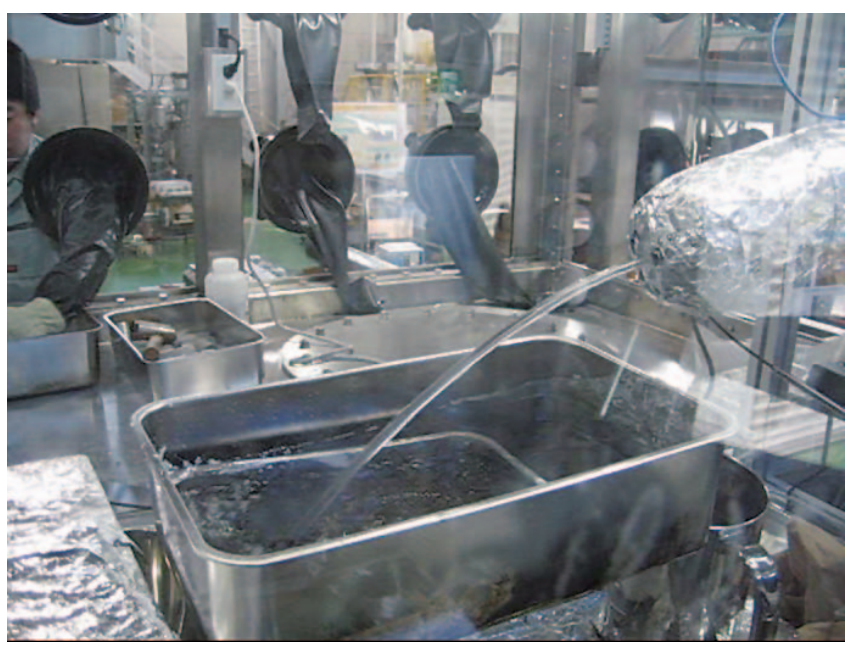

Figure 2. Photo of discharged molten LiCl- $\mathrm{KCl}$ salt flow from freeze-seal valve.

As studied in the past at ORNL and other institutes, chloride is one of the candidate salt for molten salt fast reactor that has high solubility for both actinides and fission products at operating temperature [17]. In addition, advanced pyrochemical reprocessing technologies developed in the past three decades in US, Japan and other countries for Integral Fast Reactor (IFR) $[18,19]$ can be exploited.

Engineering technologies for scaled-up process equipment such as counter current extractor and electrorefiner as well as basic data sets for actinides and FP elements in chloride molten salt are currently available [20]. Figure 2 shows a scene of an experiment to demonstrate the fluid dynamics of high temperature chloride molten salt for designing transport equipment [21]. Favorable compatibility with stainless steel at high temperature is another advantage of chloride molten salt to fluoride molten salt although the former's corrosion behavior under irradiation has not been tested yet. Based on these experiences, fuel cycle flowchart for IMSFR is proposed as

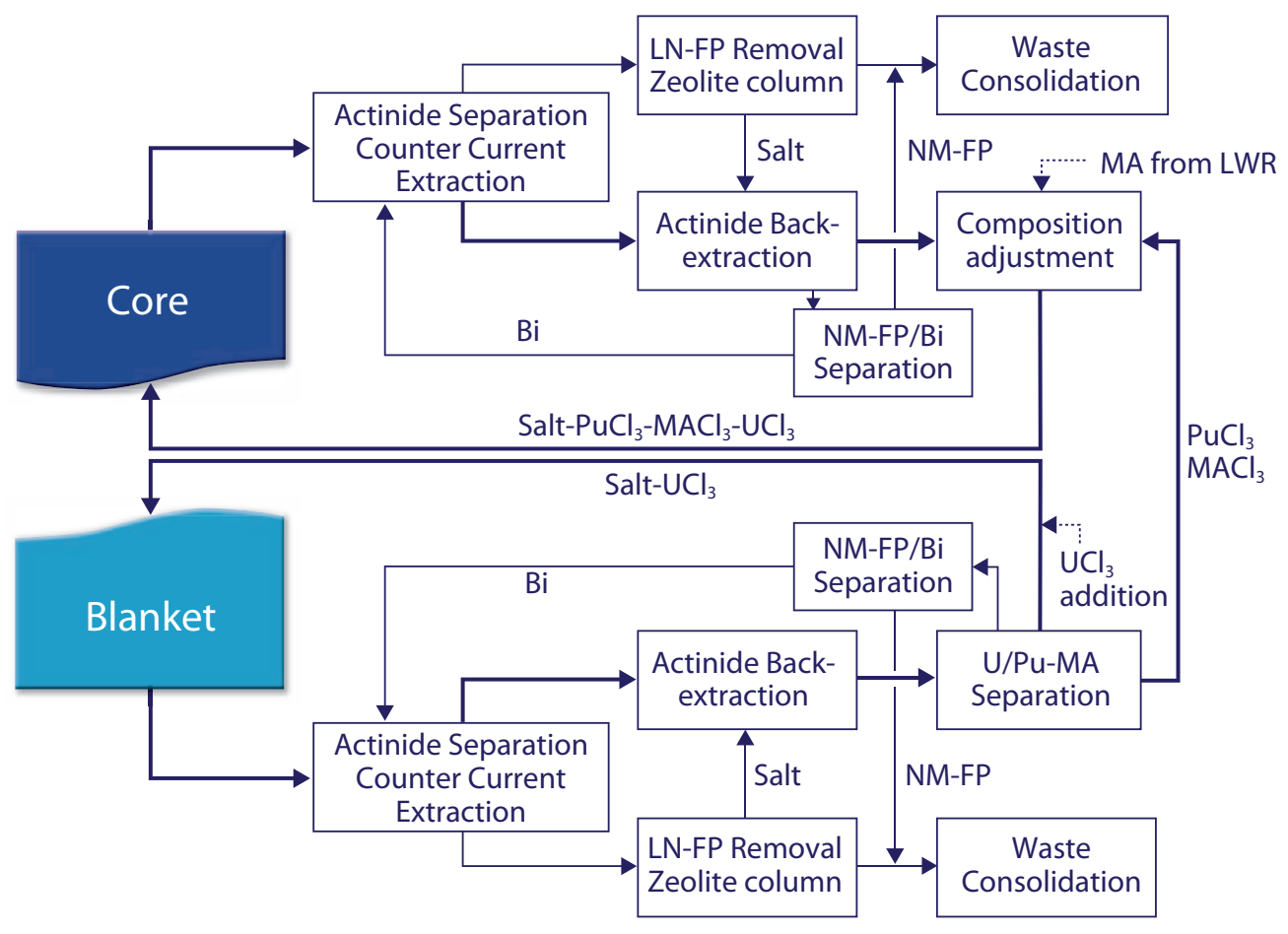

LN-FP : Less Noble FPs such as $\mathrm{Cs}, \mathrm{Sr}, \mathrm{Ce}, \mathrm{Nd}$ $\mathrm{NM}-\mathrm{FP}$ : Noble Metal FPs such as Ru, Rh, Mo, Zr

Figure 3. Proposed pyrochemical fuel cycle flowchart for IMSFR. 
TABLE 1: Characteristics of molten salt and reactor coolants

\begin{tabular}{lccccc}
\hline Material & $\begin{array}{c}\text { Melting } \\
\text { point } \\
\left({ }^{\circ} \mathrm{C}\right)\end{array}$ & $\begin{array}{c}\text { Boiling } \\
\text { point } \\
\left({ }^{\circ} \mathrm{C}\right)\end{array}$ & $\begin{array}{c}\text { Volumetric } \\
\text { heat capacity } \\
\left(\mathrm{kJ} \mathrm{m}^{-3}{ }^{\circ} \mathrm{C}\right)\end{array}$ & $\begin{array}{c}\text { Thermal } \\
\text { conductivity } \\
\left(\mathrm{W} \mathrm{m}^{-1}{ }^{\circ} \mathrm{C}\right)\end{array}$ & $\begin{array}{c}\text { Kinematic } \\
\text { Viscosity } \\
\left(\mathrm{m}^{2} \mathrm{~s}^{-1}\right)\end{array}$ \\
\hline $\mathrm{NaCl}-\mathrm{KCl}-\mathrm{MgCl}_{2}$ & 385 & 1412 & $(2511)^{*}$ & $(0.87)^{*}$ & $(1.3)^{*}$ \\
$\mathrm{NaCl}-\mathrm{KCl}-\mathrm{LiCl}$ & 388 & 1360 & $(3184)^{* *}$ & $(1.3)^{* *}$ & $(0.69)^{* *}$ \\
$\mathrm{FLiBe}$ & 459 & 1430 & 4540 & 1.0 & 2.9 \\
Liquid $\mathrm{Na}$ & 97.8 & 883 & 1000 & 62 & 0.25 \\
Liquid $\mathrm{Pb}$ & 328 & 1750 & 1700 & 16 & 0.13 \\
Water & 0 & 100 & 4040 & 0.56 & 0.13 \\
\hline
\end{tabular}

*) Estimated values for $\mathrm{NaCl}-\mathrm{KCl}-\mathrm{MgCl}_{2}-30 \%(\mathrm{U}, \mathrm{Pu}) \mathrm{Cl}_{3}[17]$

**) Estimated values for $\mathrm{LiCl}-\mathrm{RbCl}[26]$

Figure 3. From this flowchart, actinides should be separated from fission products with counter current extraction using liquid metal such as $\mathrm{Bi}$ or $\mathrm{Ga}$, while separation among actinides (U/Pu-MA) should be carried out with electrorefining. MA elements recovered from LWR spent fuel or fuel debris of defected Fukushima reactors may be introduced into IMSFR fuel cycle at composition adjustment step for transmutation at reactor core.

Toward the actual deployment of IMSFR, however, there still exist many uncertainties in development. Composition of base molten salt, which is a key issue to design the whole system such as core/blanket configuration, reactor hydraulics, reprocessing process chemistry and so on, has not been optimized yet. As a better fuel or fertile salt, selection of cation or anion of unfavorable nuclear properties such as an elastic downscatter and large neutron absorption should be avoided to keep hard neutron spectrum. According to the nuclear properties of cations by Ottewitte [22], Ca was categolized "good" and, K, Mg, and Na were "intermediate", while Li and Be were "bad". As for anion, necessity of isotope separation due to large neutron absorption of ${ }^{35} \mathrm{Cl}$ was first concerned [23], however, Nelson et al. [17] demonstrated the acceptability of natural chlorine based on their neutronics calculation. In addition, stability of liquid phase for operating temperature, from around 450 to $700{ }^{\circ} \mathrm{C}$, is necessary for the salt. According to the phase diagrams of chloride of these cations [24], ternary systems such as $\mathrm{NaCl}-\mathrm{KCl}-\mathrm{MgCl}_{2}$ and $\mathrm{NaCl}-\mathrm{KCl}-\mathrm{LiCl}$ were selected as possible candidates. As for the better reactor hydraulics, high thermal conductivity and low viscosity is favorable. Table 1 summarizes the reported characteristics of the molten salts comparing with other reactor coolants [24, 25]. The values in brackets show the reported rough estimates for similar chlorides $[17,26]$ because reliable measurements were unavailable. This table also shows the possibility to use these chlorides as coolant. For confirming the reprocessing process, distribution characteristics of relevant elements between molten salt and liquid metal or zeolite-A are needed to be assessed because chemical stability of the elements in the molten salt is different from those in LiCl-KCl. According to the measurement results reported by Koyama [27], distribution coefficients between alkali metal salt ( $\mathrm{LiCl}-\mathrm{KCl})$ and liquid $\mathrm{Cd}$ were similar to those between alkali metal - alkaline earth mixture salt ( $\left.\mathrm{LiCl}-\mathrm{KCl}-\mathrm{CaCl}_{2}-\mathrm{BaCl}_{2}\right)$ and liquid $\mathrm{Cd}$. Further study is underway for evaluation of material balance in addition to the optimization of chloride salt composition.

\section{Conclusions}

Effective reactor systems, FR, ADS and MSR, for transmutation of minor actinides from high level radioactive waste were compared with each other and MSR was estimated to be able to offer a highly efficient transmutation system. The authors have newly proposed an Integral Molten Salt Fast Reactor (IMSFR) as an enhanced efficiency transmutation system of MA for spent fuels from LWR or fuel debris from the failed nuclear reactors. IMSFR was a combination of an MSR fuelled with chloride molten salt fuel and chloride-based pyrochemical processing subsystem. Then, the fuel cycle flowchart of IMSFR had been developed. Although there were several uncertainties and issues to be solved to develop the proposed system, further studies are necessary for realizing efficient reduction of radioactive waste burden.

\section{References}

(1) K. Nishihara, "Database for Evaluation of Potential Radiotoxicity of Spent Fuel", JAEA-Data/Code 2010-012, JAEA (2010).

(2) "Accelerator-driven systems (ADS) and fast reactors (FR) in advanced nuclear fuel cycles", URL http://www.oecdnea.org/ndd/reports/2002/nea3109.html, OECD/NEA AEN, (2002).

(3) M. Yamawaki et al., $4^{\text {th }}$ chapter, NSA Commentaries No.23, "Technology Development for Decreasing the Amount and Radiotoxicity of High Level Radioactive Waste-Nuclides Separation and Transmutation",( 2016).

(4) T. Takeda, $2^{\text {nd }}$ chapter, NSA Commentaries No.23, "Technology Development for Decreasing the Amount and Radiotoxicity of High Level Radioactive Waste-Nuclides Separation and Transmutation", (2016).

(5) T. Mizuno and H. Niwa, "Advanced MOX Core Design Study of Sodium-Cooled Reactors in Current Feasibility Study on Commercialized Fast Reactor Cycle Systems in Japan”, Nucl. Tech., 146, 155 (2004).

(6) S. Ohki et al., "Fast Breeder Reactor Core Concept for Heterogeneous Minor Actinide Loading”, J. Nucl. Sci. Tech., 50, 59 (2013).

(7) "Rapport sur la gestion durable des matieres nucleaires", URL http://www.cea.fr/energie/rapport-sur-la-gestiondurable-des-matieres-nucl-106009, CEA (2012).

(8) M. Yamawaki et al., "Concept of Hydride Fuel Target Subassemblies in a Fast Reactor Core for Efficient Transmutation of MA", J. Alloys Comp., 271-273, 530533 (1998).

(9) M. Yamawaki, K. Konashi, K. Fujimura and T, Takeda, "Effective Transmutation of High Level Radioactive Waste in Fast Reactor by Using Hydride Target", J. Applied Nuclear Science and Technology, 5, Suppl., 83-88 (2012).

(10)H. Oigawa, $3^{\text {rd }}$ chapter, NSA Commentaries No.23, "Technology Development for Decreasing the Amount and Radiotoxicity of High Level Radioactive Waste-Nuclides Separation and Transmutation", (2016). 
(11) H. Oigawa et al., "Conceptual Design of Transmutation Experimental Facility", International Conference on Backend of the Fuel Cycle, GLOBAL2001, Paris, France (2001).

(12) K. Tsujimoto et al., "Feasibility of Lead-bismuth-cooled Accelerator-driven System for Minor-actinide Transmutation", Nucl. Technol., 161, 315 (2008).

(13) A. Mourogov and P.M. Bokov, "Potentialities of the fast spectrum molten salt reactor concept: REBUS-3700", Energy Conversion and Management, 47, 2761-2771 (2006).

(14) K. Mitachi, $4^{\text {th }}$ chapter, NSA Commentaries No.23, "Technology Development for Decreasing the Amount and Radiotoxicity of High Level Radioactive Waste-Nuclides Separation and Transmutation", (2016).

(15) M. Yamawaki, Y. Arita et al., "New Concept of StaticFuel-Type Molten Salt Reactor", Proc. ICONE-23, May 17-21,2015, Chiba, Japan (2015).

(16) M. Yamawaki, Plenary Lecture, $3^{\text {rd }}$ Japan-China Academic Symposium on Nuclear Fuel Cycle (ASFNC2015), Dec.25, 2015, Tokyo, Japan (2015).

(17) P.A. Nelson, et al., "Fuel properties and nuclear performance of fast reactors fueled with molten chlorides", Nuclear Applications, 3: 540-547, September 1967.

(18) Y. I. Chang, "The Integral Fast Reactor", Nuclear Technology, Vol.88, 129-138(1989).

(19) T. Koyama, "Chapter 10: Nuclear technology for pyrochemical treatment of spent nuclear fuels", p.267-310, K.L.Nash and G.J.Lumetta edited, "Advanced separation technique for nuclear fuel reprocessing and radioactive waste treatment", Woodhead Publishing, ISBN: 978-184569-501-9 (2011).
(20) T. Koyama and M. Iizuka, “Chapter 18: Pyrochemical fuel cycle technologies for processing spent nuclear fuels: developments in Japan", p.457-520, R. Taylor edited, "Reprocessing and recycling of spent nuclear fuel", Woodhead Publishing, ISBN 978-78242-212-9 (2015).

(21) T. Hijikata and T. Koyama, "Development of high-temperature molten salt transport technology for pyrometallurgical reprocessing", J. Power Energy Syst. 3 (1), 170181(2009).

(22)E. H. Ottewitte, "Cursory First Look at the Molten Chloride Fast Reactor as an Alternative to the Conventional BATR Concept", ANL, (1992).

(23) J.J. Bulmer, E.H. Gift, R.J. Roll, A.M. Jacobs, S. Jaye, E. Kassman, R.L. McVean, R.G. Oehl, and R.A. Rossi, "Fused Salt Fast Breeder," CF-56-8-204 (Del) Oak Ridge School of Reactor Technology, Oak Ridge, Tennessee (1956).

(24) P.Chartrand and A. D. Pelton, "Thermodynamic Evaluation and Optimization of the LiCl-NaCl-KCl-RbCl- $\mathrm{MgCl}_{2}-$ $\mathrm{CaCl}_{2}$ System Using the Modified Quasi-chemical Model", Metallurgical and Materials Transactions A, 32A, 13611383(2001).

(25)C.W.Forsberg, "Reactors with Molten Salts: Options and Missions", Material for Frederic Oliot \& Otto Han Summer School on Nuclear Reactors "Physics, Fuels, and Systems", Cadarache, France, Aug.25-Sept. 3, 2004.

(26)D.F.Williams, "Assessment of Candidate Molten Salt Coolants for the NGNP/NHI Heat-Transfer Loop", ORNL/ TM-2006/69, (2006).

(27) T. Koyama, T. Johnson and D. F. Fischer, "Distribution of actinides in molten chloride salt /cadmium metal systems", Journal of Alloys and Compounds, 189(1), 37-44 (1992). 